\title{
The true penalty of the waiting room: the role of wait time in patient satisfaction in a busy spine practice
}

\author{
Rasheedat T. Zakare-Fagbamila, MD,, ${ }^{1}$ Christine Park, BA, ${ }^{2}$ Wes Dickson, BSE, ${ }^{3}$ \\ Tracy Z. Cheng, MD, MHS, ${ }^{4}$ and Oren N. Gottfried, MD ${ }^{2}$
}

\begin{abstract}
'Department of Neurosurgery, University of Florida, Gainesville, Florida; ${ }^{2}$ Department of Neurosurgery, Duke University Medical Center; ${ }^{3}$ Department of Performance Services, Duke University Health System, Durham, North Carolina; and ${ }^{4}$ Department of Otolaryngology, University of Pittsburgh, Pittsburgh, Pennsylvania
\end{abstract}

\begin{abstract}
OBJECTIVE Most clinics collect routine data on performance metrics on physicians for outpatient visits. However, the relationship of these metrics with patient experience is unclear. The goal of this study was to investigate the relationships between the Consumer Assessment of Healthcare Providers and Systems Clinician and Group Survey (CG-CAHPS), the standard patient experience survey, and clinic performance metrics to understand the determinants of patient satisfaction and identify targets for improving patient experience.
\end{abstract}

METHODS The authors performed a retrospective single-institution cohort review of spine surgeon metrics over 15 months including demographics, waiting-room times, in-room times, lead times, timely note closure, timely MyChart responses, and monthly patient volume. Kruskal-Wallis tests and mixed-model regression were used to determine the predictors of 3 domains of patient satisfaction-Global, Access, and Communication.

RESULTS Over 15 months, 22 surgeons conducted 27,090 visits. The average clinic visit total time was $85.17 \pm 25.75$ minutes. Increased wait times were associated with poor Global $(p=0.008)$, Access $(p<0.001)$, and Communication scores $(p=0.003)$ in univariate analysis. Every 10 -minute increase in waiting time was associated with a $3 \%, 9.8 \%$, and $2.4 \%$ decrease in Global, Access, and Communication scores, respectively. Increased in-room time was also an independent predictor of poor Access scores $(p<0.001)$. In multivariate analysis, increased wait times were negative predictors of Global ( $p=0.005)$, Access $(p<0.001)$, and Communication $(p=0.002)$ scores.

CONCLUSIONS Excessive waiting-room time significantly impacts unexpected dimensions of the patient experience and impacts communication with patients. Understanding the complex relationship between the factors that inform the patient experience will help target effective interventions to improve clinic efficiency and patient satisfaction.

https://thejns.org/doi/abs/10.3171/2019.12.SPINE191257

KEYWORDS Consumer Assessment of Healthcare Providers and Systems Clinician and Group Survey; CG-CAHPS; cycle time; patient experience; patient satisfaction; spine clinic

$\mathrm{C}$ LINIC practices are constantly assessed for profitability, for operational standards such as access to care and efficiency, and-most importantly-for delivering high-quality healthcare and patient satisfaction as measured by the Consumer Assessment of Healthcare Providers and Systems Clinician and Group Survey (CGCAHPS). ${ }^{15,27,39}$ These financial concerns exert forces on physicians to see more patients in less time and to meet specific quantitative performance metrics, which may not necessarily align with providing excellent care. Performance metrics for clinics and physicians may parameterize financial, process, and patient-reported outcomes. ${ }^{26}$
There is substantial reporting on the current inefficiency of many practices: for example, clinics are faulted for not only keeping patients waiting for long periods of time but also spending short amounts of actual clinical care time with individual patients. ${ }^{24}$ Suggestions have been presented both formally and informally as solutions to improve the patient experience by becoming more efficient, but it is important to first understand if and how these different concepts are related before significantly disrupting clinical practice by implementing large changes.

There have been several studies outside of neurosurgery that suggest a relationship between these quality

ABBREVIATIONS BH = Benjamini-Hochberg; CG-CAHPS = Consumer Assessment of Healthcare Providers and Systems Clinician and Group Survey; PCP = primary care provider. 
measures.,31 For example, long wait times and poor interactions with clinicians have been shown to hurt general outpatient satisfaction scores, while administrative indicators such as access to care and readmissions have been correlated with clinical outcomes after hospital discharge. These relationships are important to identify in clinical settings for multiple reasons: they clarify areas for targeted improvement that can improve the quality of care from multiple perspectives, identify conflicting values between perspectives, and may prevent erroneous assumptions from being made about what patients value. ${ }^{2,44}$

For spine surgery at our institution, the objective of this study was to answer three specific questions, as follows. 1) Is there any relationship between satisfaction and process measures for our population of spine surgeons and their patients? 2) Are the relationships present at this institution comparable to those at other institutions? 3) Can the relationships between patient and clinic variables be used to create a useful model of patient satisfaction?

\section{Methods}

This study has been approved by the institutional review board at Duke. Patient consent was not sought because patients were not subjected to any intervention resulting from this study. Results were reported using the Strengthening the Reporting of Observational studies in Epidemiology (STROBE) statement. ${ }^{11}$

\section{Patient Population}

This was a single-center, retrospective cohort analysis of all spine surgeons within our academic health system, including both neurosurgeons and orthopedic surgeons at 3 practice locations. The department, subspecialty, years of experience, fellowship training, and sex of each surgeon were publicly available. We collected monthly data over 15 months for outpatient metrics followed by our clinic performance team that are used as internal measures of clinic efficiency and performance. These include overall time from check-in to check-out in minutes ("cycle time"), the time it took to room a patient from check-in in minutes ("waiting-room time"), the time patients were in the room until check-out in minutes ("in-room time"), the proportion of notes that were closed in a timely manner, the proportion of electronic patient messages that were replied to in a timely manner, the time in days from appointment request to appointment ("lead time"), the proportion of patients seen who used MyChart (the online patient interface for the Epic EMR), the proportion of patients seen who had a primary care provider (PCP) on file, total new visits, and the total of overall visits. All time stamps were routinely collected by nurses in our clinic.

The outcome measures were the CG-CAHPS Access, Global, and Communication scores, as well as the results for individual questions within those composite scores. Global ratings are based on a single question asking patients to rate providers from 0 to 10 . The monthly score for a provider is the proportion of patients who gave a 9 or 10 out of 10 score.

Access question 5 (i.e., Access-5) asks the patient to recall if they were able to see their provider within 15 minutes of their appointment time. Physician scores were calculated as the proportion of patients in that month who answered in the affirmative. The other Access questions were not included in this analysis.

Communication scores were a composite of 6 different questions (i.e., Communication-1 through -6), as follows. 1) Provider explained things in a way that was easy to understand. 2) Provider listened carefully to patient. 3) Provider gave easy-to-understand information about health questions or concerns. 4) Provider knew important information about patient's medical history. 5) Provider showed respect for what patient had to say. 6) Provider spent enough time with patient. We analyzed the relationship between our clinical variables and each of the communication questions as well as the composite communication score.

All analyses were performed in RStudio v1.1.422. Kruskal-Wallis testing was used for categorical variables and univariate mixed-model regression was used for continuous variables in single-variable analyses. Multivariate mixed-model regression was used for the complete models. Mixed-model regression with the individual surgeon as the blocking variable was used due to repeated measures within the same population of surgeons. Significance and false discovery rate were set at 0.05 , and the BenjaminiHochberg $(\mathrm{BH})$ method was used to correct for multiple comparisons in the univariate models. ${ }^{6}$ Pearson correlation coefficients were calculated for a linear relationship between wait time and outcome variables if the mixedmodel regression was significant at the $\alpha=0.05$ level.

\section{Results \\ Overall Performance}

During the 15 months of observation, 22 neurosurgical and orthopedic spine surgeons conducted 27,090 patient encounters and generated 272 provider-months of data. The majority of surgeons were male $(86 \%)$, trained in neurosurgery $(68 \%)$, and fellowship trained (68\%) (Table 1). The mean monthly clinic characteristics are also shown in Table 1.

\section{Global Scores}

In univariate analysis, among nonmodifiable traits, fellowship training and female sex were negatively associated with Global scores $(\mathrm{p}<0.001)$ (Table 2). Overall cycle time $(\mathrm{p}=0.004)$ and increased waiting-room time $(\mathrm{p}=$ $0.008)$, but not in-room time $(\mathrm{p}=0.05)$, were significant predictors of poor Global scores (Fig. 1). In the multivariate analysis sex was no longer significant. However, waiting-room time remained significant $(\mathrm{p}=0.005)$, and the proportion of patients who had a PCP on file also emerged as a significant positive predictor $(\mathrm{p}=0.01)$ (Table 2$)$.

\section{Access- 5 Scores}

In univariate analysis there were no nonmodifiable characteristics that predicted Access-5 scores (Table 3). Longer overall cycle times, waiting-room times, and inroom times were all significant predictors of lower Access-5 scores $(\mathrm{p}<0.001)$. A 10 -minute increase in waitingroom time was associated with a $9.8 \%$ absolute decrease 
TABLE 1. Surgeon demographics and clinic characteristics

\begin{tabular}{lc}
\hline \multicolumn{1}{c}{ Variable } & Value \\
\hline \multicolumn{2}{c}{ Surgeon demographics } \\
\hline Sex \\
\hline Male \\
\hline Female \\
\hline Specialty \\
\hline Neurosurgery \\
\hline Orthopedic surgery \\
\hline Fellowship \\
\hline Experience, yrs (median, IQR) \\
\hline Clinic characteristics \\
\hline Cycle time, mins (mean \pm SD) \\
\hline Waiting-room time, mins (mean \pm SD) \\
\hline In-room time, mins (mean \pm SD) \\
\hline Lead time, days (mean \pm SD) \\
\hline Timely closed notes & $15(32 \%)$ \\
\hline Patient MyChart utilization rate & $6.5(3.25,15.74 \pm 17 \pm 25.75$ \\
\hline Patient PCP utilization rate & $64.00 \pm 18.92$ \\
\hline Monthly total patient vol (mean \pm SD) & $17.87 \pm 10.43$ \\
\hline Monthly new patient vol (mean \pm SD) & $80 \%$ \\
\hline
\end{tabular}

$I Q R=$ interquartile range.

in Access-5 scores (Fig. 2). In multivariate analysis, both waiting-room time and in-room time were significant and independent predictors of lower Access-5 scores (Table $3)$. A 10-minute increase in waiting-room time was correlated with a $7.87 \%$ absolute drop in scores $(\mathrm{p}<0.001)$; a 10-minute increase in in-room time correlated with a separate $4.06 \%$ drop in scores $(\mathrm{p}=0.002)$.

\section{Communication Scores}

In univariate analysis, specialty, month, fellowship training, and sex were all statistically significant predictors of overall Communication scores (Table 4). Overall cycle time was also a significant negative predictor $(-1.23 \% / 10$ minutes, $\mathrm{p}=0.004)$. However, after being split into its components, in-room time was not significant, whereas waiting-room time was $(-2.37 \% / 10$ minutes, $\mathrm{p}=$ 0.003 ) (Fig. 3). In multivariate analysis, waiting-room time held as a predictor, with an absolute decrease of $2.74 \%$ per additional 10 minutes $(p=0.002)$. Furthermore, patient PCP utilization rate was positively correlated with higher score (Table 4).

Clinic cycle time remained a significant predictor across all questions except Communication-3. Waitingroom time was an independent predictor for Communication-1, $-2,-5$, and -6 (Table 5). In-room time was an independent predictor for Communication-1 only. In all cases, increased time was associated with lower scores.

\section{Integrated Model of Patient Satisfaction}

A review of the literature reveals several other contributors in addition to our own findings, and we propose a new model for patient satisfaction in the outpatient set- ting. In our model a patient's intrinsic characteristics, including individual demographics, disease diagnosis, and overall health status establish patient preferences a priori. ${ }^{10,34,37}$ The patient then forms expectations prior to the visit based on available information in 4 major extrinsic categories: their doctor's characteristics,,${ }^{9,42}$ the reputation of the practice or institution, ${ }^{8,20}$ their own prior experience with the doctor/institution, and their chief complaints. ${ }^{39}$ These expectations, in a multifactorial fashion, influence the interpretation of 4 major domains of experience during the visit: their interaction with the doctor, their interaction with the staff, the logistics of the visit itself, and the resolution of their chief complaints. ${ }^{33}$ Logistics include scheduling the visit, the convenience of the location and parking, paperwork, and waiting time in between interactions - the last of which is parameterized in this study as overall cycle time, waiting-room time, and in-room time. ${ }^{13,36}$

\section{Discussion \\ Key Findings}

The primary objective of this study was to determine which outpatient performance metrics were predictive of patient experience measures. In our population of 22 spine surgeons at our institution we found that, among modifiable factors, protracted cycle time-time spent both in the waiting room and in the examination room-resulted in not only lower Access scores but in significantly lower Global ratings and Communication scores as well.

\section{Interpretation of Findings}

The secondary objective of this study was to inform and supplement our overall understanding of the effect of wait time on nonlogistical measures of patient satisfaction. Our results are important because they demonstrate clearly that increased waiting-room time impairs surgeon-patient communication. The mechanism connecting wait time to communication issues may be rooted on the patient side in the fact that ongoing pain and neurological symptoms are endemic to our spine surgery population. Evidence shows that patients with chronic pain secondary to their condition have latent anger and frustration at baseline; these feelings are almost certainly aggravated by long wait times in clinic. ${ }^{14,17}$ Low-level anger has been shown to modulate attention, increase passive-aggressive behaviors, and influence the perception of time, which leaves patients retaining less information or feeling that they received less time with their provider. ${ }^{19,21}$ On the physician side, frustration with clinic flows can stimulate similar behavioral patterns. ${ }^{5,30}$ Even outside of disease-related issues, patients are additionally burdened by scheduling, parking, long wait times, and difficulty communicating with the office. $7,13,25$

These facts explain why cycle time was correlated with individual communication questions. Surgeons may have received poor scores for "spends enough time" because patients spending more time in the examination room does not equal time spent usefully or perceived in relation to time in the waiting room. To better understand this result, it is important to avoid the trap of the so-called ecological fallacy that the patients' desire for more time with 
TABLE 2. Univariate and multivariate predictors of global rating for surgeons

\begin{tabular}{|c|c|c|c|}
\hline Global univariate predictors, $n=250$ & Mean Score & SD & $\mathrm{p}$ Value \\
\hline Specialty & & & 0.004 \\
\hline Spine & 0.86 & 0.15 & \\
\hline Functional & 0.91 & 0.16 & \\
\hline Department* & & & 0.03 \\
\hline Orthopedics & 0.86 & 0.13 & \\
\hline Neurosurgery & 0.87 & 0.17 & \\
\hline Fellowship & & & $<0.001$ \\
\hline Yes & 0.85 & 0.14 & \\
\hline No & 0.90 & 0.17 & \\
\hline Sex & & & $<0.001$ \\
\hline Male & 0.88 & 0.15 & \\
\hline \multirow[t]{2}{*}{ Female } & 0.80 & 0.15 & \\
\hline & Mean Effect & SE & $\mathrm{p}$ Value \\
\hline Month & 0.0032 & 0.0021 & 0.13 \\
\hline Experience & 0.0019 & 0.0017 & 0.28 \\
\hline Timely note closure rate & -0.036 & 0.061 & 0.56 \\
\hline Cycle time & $-0.0017 \dagger$ & 0.0006 & 0.004 \\
\hline Waiting-room time (mins) & $-0.0030 \ddagger$ & 0.0011 & 0.008 \\
\hline In-room time (mins) ${ }^{*}$ & $-0.0015 \S$ & 0.0008 & 0.05 \\
\hline Timely in-basket response rate & -0.033 & 0.046 & 0.48 \\
\hline Lead time (days) & -0.00032 & 0.0011 & 0.77 \\
\hline Patient MyChart utilization rate & -0.135 & 0.120 & 0.26 \\
\hline Patient PCP utilization rate & 0.341 & 0.190 & 0.07 \\
\hline Monthly new visits & -0.00021 & 0.00067 & 0.75 \\
\hline Monthly total visits & -0.000045 & 0.00019 & 0.81 \\
\hline Global multivariate predictors, $n=227$ & Mean Score & SD & p Value \\
\hline Intercept & 0.62 & 0.20 & 0.003 \\
\hline Spine specialty (ref = Functional) & -0.03 & 0.05 & 0.54 \\
\hline Orthopedic surgery (ref = Neurosurgery) & -0.03 & 0.04 & 0.46 \\
\hline Month & 0.004 & 0.002 & 0.10 \\
\hline Experience (yrs) & 0.002 & 0.002 & 0.27 \\
\hline Female surgeon & -0.07 & 0.05 & 0.16 \\
\hline Timely note closure rate & -0.06 & 0.06 & 0.38 \\
\hline Waiting-room time (mins) & $-0.00352 \pi$ & 0.001 & 0.005 \\
\hline In-room time (mins) & $-0.00089^{* *}$ & 0.001 & 0.28 \\
\hline Timely in-basket response rate & -0.04 & 0.05 & 0.41 \\
\hline Lead time (days) & -0.0003 & 0.001 & 0.83 \\
\hline Patient MyChart utilization rate & -0.06 & 0.14 & 0.66 \\
\hline Patient PCP utilization rate & 0.55 & 0.20 & 0.01 \\
\hline Monthly new visits & 0.0001 & 0.001 & 0.94 \\
\hline Monthly total visits & 0.0002 & 0.0003 & 0.54 \\
\hline $\begin{array}{l}\text { Boldface type indicates statistical significance. } \\
\text { * Not significant after } \mathrm{BH} \text { correction. } \\
\dagger-1.7 \% \text { per } 10 \text { minutes. } \\
\ddagger-3.0 \% \text { per } 10 \text { minutes. } \\
\S-1.5 \% \text { per } 10 \text { minutes. } \\
\text { \ी }-3.52 \% \text { per } 10 \text { minutes. } \\
* *-0.89 \% \text { per } 10 \text { minutes. }\end{array}$ & & & \\
\hline
\end{tabular}




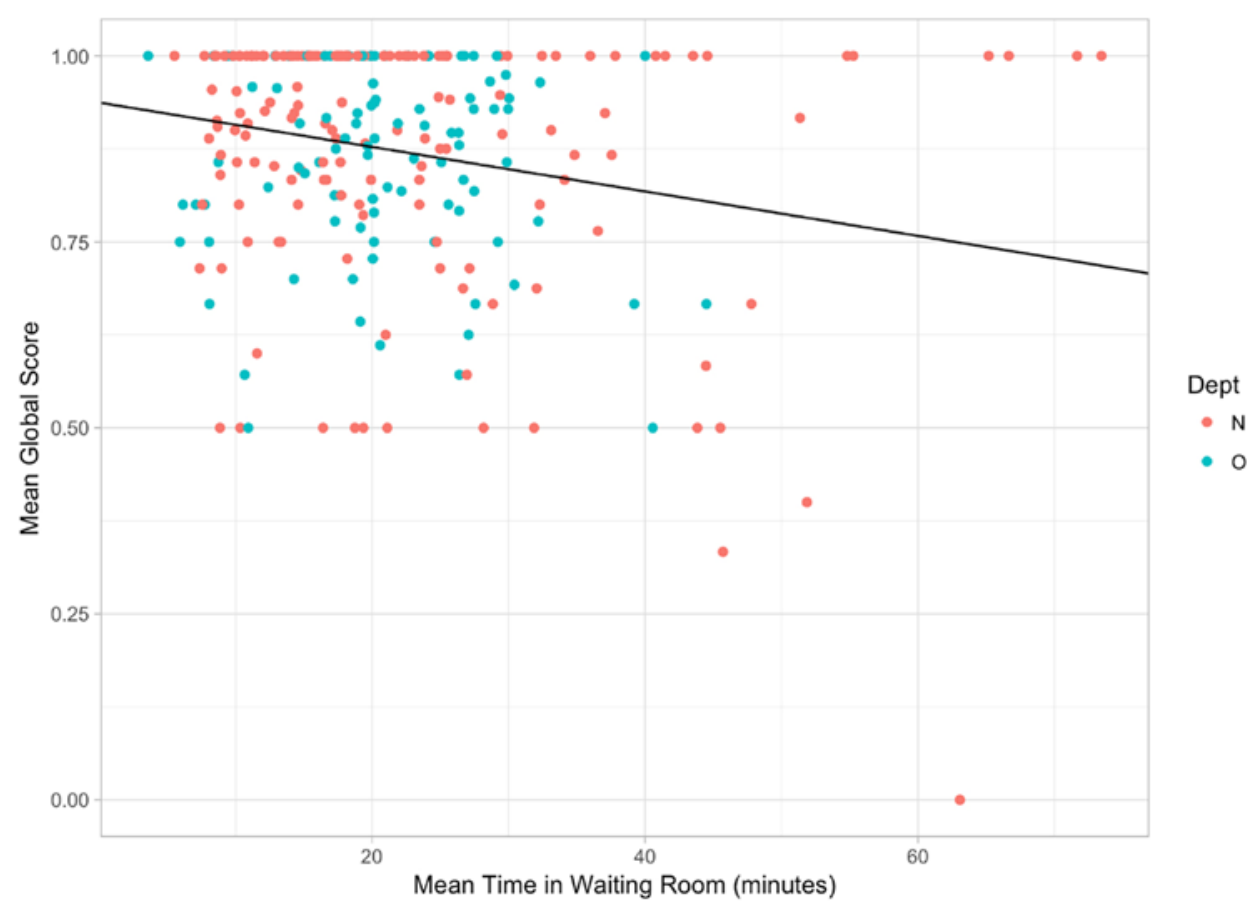

FIG. 1. Global rating as a function of wait time. Across all providers and encounters, prolonged average waiting time was associated with a $2.99 \%$ absolute reduction in global rating scores per 10 additional minutes of waiting in univariate mixed-methods regression. Dept $=$ department; $N=$ neurosurgery $($ red dots); $\mathrm{O}=$ orthopedic surgery $($ blue dots). $\mathrm{R}=-0.18, p=0.0056$. Figure is available in color online only.

the provider does not translate to longer time in the examination room. 18,43 "Clear explanations" may get poor scores because angry and frustrated patients are not able to pay as much attention, and physicians, frustrated perhaps by long wait times or overbooked clinics, are not taking the time to explain better..$^{30}$ Patients may rate surgeons poorly for "knowing medical history" and "careful listening" because it seems to them that surgeons are busy looking them up in the chart before and during the visit. Whether or not these effects are due to physician or patient responses to frustration with long wait times, the responsibility lies with the clinics to improve the root cause.

Our results also reiterate that waiting-room time is a modifiable factor that is a significant contributor to global satisfaction. This has been demonstrated both in other spine practices and in specialties outside of spine surgery. ${ }^{12,27,31,35-37}$ This is important because overall satisfaction has been shown to influence downstream patient behavior: patients who are less satisfied are less likely to schedule follow-up clinic visits, more likely to use emergency services, and less likely to adhere to medications and treatment recommendations. ${ }^{4,22,37}$

So how do we improve wait times and the perception thereof? We must address the underlying causes of an inefficient clinic. Some logistical issues have been identified, such as appointment type, late doctor arrival, and early-arriving patients who wait long periods until their actual appointment time. ${ }^{1,23}$ Communication delays are also a significant source of problems and are frustrating to patients. ${ }^{41}$

There have been several interventions that have dem- onstrated the proof of these concepts, many of which were rooted in the basic principles of quality and process improvement. In order to create an effective intervention, a team must analyze the factors contributing to clinic delays, improve those processes, reduce variability within those processes, and then address the psychology among all stakeholders about delays. ${ }^{28}$ Some specific methods of doing so use plan-do-study-act (PDSA) cycles, leanmanufacturing principles, and lean and 5-sigma strategies. ${ }^{25,32,38,40}$ Addition of physician extenders including physician assistants and nurse practitioners to the healthcare team has also been shown to improve patient satisfaction with their visit as well as healthcare staff satisfaction in communication with families and clinical documentations. ${ }^{29}$ Each intervention, including our own suggestions listed below, is not strictly generalizable because the factors present within each health system will be unique at both a system and provider level, but they do provide a framework for addressing those factors. ${ }^{3,19}$

In our own clinic we have identified and addressed some areas for improvement that may be helpful for other practices to consider, including the following.

- Using the Clinic Satisfaction Tool to solicit chief complaints up front during the visit and reduce door handle delays ${ }^{45}$

- Chart reviewing complete list before clinic day and dictating notes after, not in between, patient visits

- Limiting the total number of patients seen on a given day

- Employing more physician extenders to conduct initial patient interviews 
TABLE 3. Univariate and multivariate predictors of Access-5 rating

\begin{tabular}{|c|c|c|c|}
\hline Access -5 univariate predictors, $n=250$ & Mean Score & SD & $\mathrm{p}$ Value \\
\hline Specialty & & & 0.13 \\
\hline Spine & 0.71 & 0.25 & \\
\hline Functional & 0.63 & 0.30 & \\
\hline Department* & & & 0.18 \\
\hline Orthopedics & 0.68 & 0.21 & \\
\hline Neurosurgery & 0.70 & 0.28 & \\
\hline Fellowship & & & 0.13 \\
\hline Yes & 0.70 & 0.24 & \\
\hline No & 0.68 & 0.29 & \\
\hline Sex & & & 0.27 \\
\hline Male & 0.69 & 0.25 & \\
\hline \multirow[t]{2}{*}{ Female } & 0.73 & 0.26 & \\
\hline & Mean Effect & SE & $\mathrm{p}$ Value \\
\hline Month* & 0.0065 & 0.0032 & 0.04 \\
\hline Experience & -0.0039 & 0.0034 & 0.26 \\
\hline Timely note closure rate & -0.011 & 0.10 & 0.91 \\
\hline Cycle time & $-0.0060 \dagger$ & 0.00075 & $<0.001$ \\
\hline Waiting-room time (mins) & $-0.0098 \ddagger$ & 0.0017 & $<0.001$ \\
\hline In-room time (mins) & $-0.0064 \S$ & 0.0010 & $<0.001$ \\
\hline Timely in-basket response rate & 0.028 & 0.074 & 0.71 \\
\hline Lead time (days) & -0.0012 & 0.0017 & 0.50 \\
\hline Patient MyChart utilization rate & -0.34 & 0.19 & 0.09 \\
\hline Patient PCP utilization rate & 0.36 & 0.30 & 0.23 \\
\hline Monthly new visits & -0.0016 & 0.0011 & 0.14 \\
\hline Monthly total visits & -0.00049 & 0.00032 & 0.13 \\
\hline Access- 5 multivariate predictors, $n=227$ & Mean Score & SD & $\mathrm{p}$ Value \\
\hline Intercept & 0.78 & 0.31 & 0.01 \\
\hline Spine specialty (ref = Functional) & 0.10 & 0.08 & 0.25 \\
\hline Orthopedic surgery (ref = Neurosurgery) & -0.04 & 0.07 & 0.59 \\
\hline Month & 0.001 & 0.003 & 0.75 \\
\hline Experience (yrs) & 0.002 & 0.003 & 0.45 \\
\hline Female surgeon & -0.05 & 0.08 & 0.55 \\
\hline Timely note closure rate & 0.02 & 0.10 & 0.80 \\
\hline Waiting-room time (mins) & $-0.00787 \pi$ & 0.002 & $<0.001$ \\
\hline In-room time (mins) & $-0.00406^{* *}$ & 0.001 & 0.002 \\
\hline Timely in-basket response rate & 0.02 & 0.07 & 0.75 \\
\hline Lead time (days) & -0.0003 & 0.002 & 0.88 \\
\hline Patient MyChart utilization rate & -0.23 & 0.21 & 0.26 \\
\hline Patient PCP utilization rate & 0.49 & 0.30 & 0.11 \\
\hline Monthly new visits & -0.001 & 0.002 & 0.62 \\
\hline Monthly total visits & -0.0003 & 0.001 & 0.55 \\
\hline 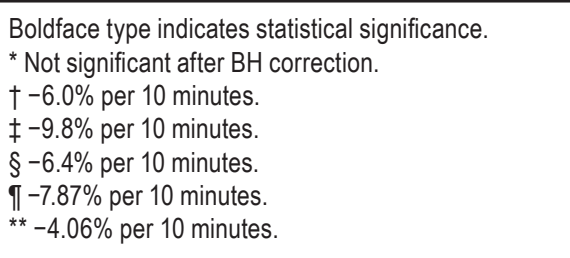 & & & \\
\hline
\end{tabular}




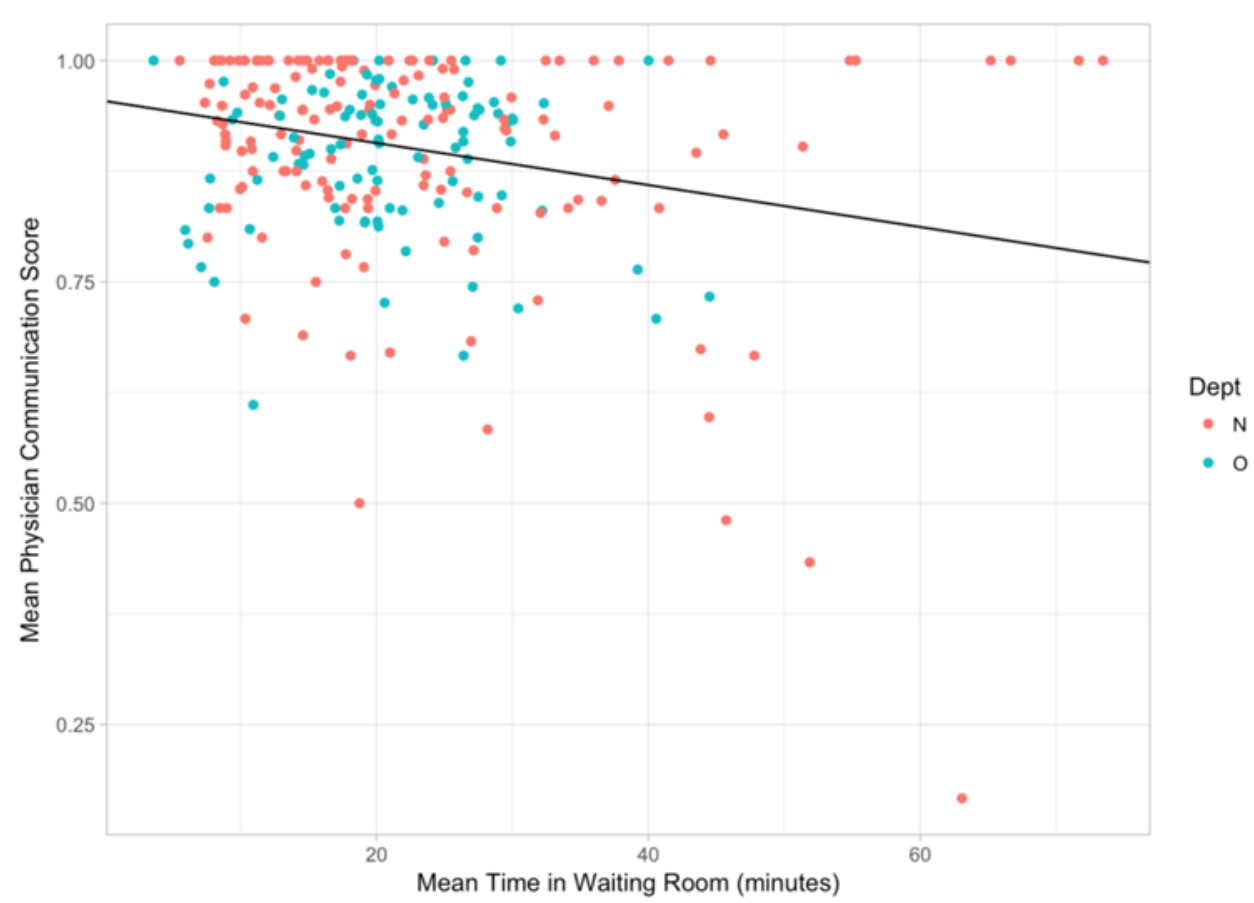

FIG. 2. Access- 5 rating as a function of wait time. Across all providers and encounters, prolonged average waiting time was associated with a 9.84\% absolute reduction in Access question 5 scores per 10 additional minutes of waiting in univariate mixed-methods regression. Red dots indicate neurosurgery department and blue dots indicate orthopedic surgery department. $R=-0.32, p<$ 0.0001 . Figure is available in color online only.

- Incorporating breaks within the schedule to allow staff to catch up with patient visits

- Real-time tracking of patient location in clinic to pinpoint bottleneck in traffic

- Improving communication between front and back nursing and staff ${ }^{13}$

- Enriching the waiting-room experience with pleasant décor, distractions, and refreshments ${ }^{11}$

All of these interventions have worked because there is some true connection between wait times and a satisfactory patient experience, modulated by and interacting with several other factors, as illustrated in our proposed model.

Additionally, connection with a PCP had a positive impact on both Global and Communication scores. Not only do PCPs help patients cope better with their chronic conditions as the first line of contact in their care, ${ }^{16}$ but they also provide longitudinal care that translates to greater overall satisfaction with care and higher Global score. Furthermore, PCPs exercise great responsibility in the successful delivery of integrated care to patients. Hence, a good relationship between patients and their PCPs can result in better coordination of treatment and timely follow-ups that increase patients' perceptions of quality of care and that influence the Communication score.

A survey like the CG-CAHPS does not perfectly capture the 4 patient-centered domains we identified: doctor experience, staff experience, visit logistics, and resolution of the chief complaints. Instead, CG-CAHPS explores 3 themes relevant to this discussion that are each influenced in different degrees by multiple domains of experience. The Global score is, based on the general nature of the question, likely to be an amalgamation of both the interaction with the doctor and the chief complaints. The Access score is based on staff interactions and logistics because these are the questions directly asked. Last, the Communication score, which in an ideal situation would capture only interaction with the doctor and resolution of the chief complaints (in the sense of properly communicating the plan with the patient), seems also to be capturing logistical issues, based on our findings.

This framework is important because it allows us to target specific areas to improve patient satisfaction, either in managing expectations or in improving the experience, and it also directs us to where we should look for downstream effects. Future study looking into the association between physician quality score and cycle time in its impact on patient satisfaction scores is warranted.

\section{Limitations of the Study}

The limitations of our findings are based mainly on variations between physicians in key encounter events. Because our center is a major academic facility, our inroom time may include interactions with nursing, medical students, residents, advanced practice providers, and attendings, as well additional waiting-room time between any of these encounters. Another limitation of the study is the measurement of cycle time, waiting-room time, and in-room time. Time started when patients checked in and ended when they checked out, and we rely on clinic staff to accurately document when patients are roomed. Last, months in which providers had fewer CG-CAHPS materials returned caused floor/ceiling effects in the response 
TABLE 4. Univariate and multivariate predictors of communication rating

\begin{tabular}{|c|c|c|c|}
\hline Communication rating univariate predictors, $n=250$ & Mean Score & SD & p Value \\
\hline Specialty & & & 0.004 \\
\hline Spine & 0.89 & 0.11 & \\
\hline Functional & 0.93 & 0.10 & \\
\hline Department* & & & 0.03 \\
\hline Orthopedics & 0.89 & 0.084 & \\
\hline Neurosurgery & 0.90 & 0.13 & \\
\hline Fellowship & & & $<0.001$ \\
\hline Yes & 0.88 & 0.11 & \\
\hline No & 0.93 & 0.12 & \\
\hline Sex & & & $<0.001$ \\
\hline Male & 0.91 & 0.11 & \\
\hline \multirow[t]{2}{*}{ Female } & 0.86 & 0.093 & \\
\hline & Mean Effect & SE & p Value \\
\hline Month & 0.0041 & 0.0014 & 0.004 \\
\hline Experience & 0.00092 & 0.0014 & 0.51 \\
\hline Timely note closure rate & 0.0052 & 0.042 & 0.90 \\
\hline Cycle time & $-0.0012 \dagger$ & 0.00042 & 0.004 \\
\hline Waiting-room time (mins) & $-0.0024 \ddagger$ & 0.00079 & 0.003 \\
\hline In-room time (mins) & $-0.00090 \S$ & 0.00056 & 0.11 \\
\hline Timely in-basket response rate & -0.019 & 0.032 & 0.55 \\
\hline Lead time (days) & 0.00024 & 0.00077 & 0.76 \\
\hline Patient MyChart utilization rate & -0.079 & 0.085 & 0.35 \\
\hline Patient PCP utilization rate & 0.19 & 0.133 & 0.16 \\
\hline Monthly new visits & -0.000073 & 0.00047 & 0.88 \\
\hline Monthly total visits & -0.000014 & 0.00014 & 0.92 \\
\hline Communication rating multivariate predictors, $n=227$ & Mean Score & SD & p Value \\
\hline Intercept & 0.73 & 0.15 & $<0.001$ \\
\hline Spine specialty (ref = Functional) & -0.03 & 0.04 & 0.46 \\
\hline Orthopedic surgery (ref = Neurosurgery) & -0.01 & 0.03 & 0.76 \\
\hline Month & 0.004 & 0.002 & 0.01 \\
\hline Experience (yrs) & 0.001 & 0.001 & 0.46 \\
\hline Female surgeon & -0.04 & 0.04 & 0.28 \\
\hline Timely note closure rate & 0.001 & 0.04 & 0.98 \\
\hline Waiting-room time (mins) & $-0.00274 \rrbracket$ & 0.001 & 0.002 \\
\hline In-room time (mins) & $-0.00070^{* *}$ & 0.001 & 0.25 \\
\hline Timely in-basket response rate & -0.04 & 0.03 & 0.28 \\
\hline Lead time (days) & 0.0001 & 0.001 & 0.90 \\
\hline Patient MyChart utilization rate & -0.03 & 0.10 & 0.75 \\
\hline Patient PCP utilization rate & 0.34 & 0.14 & 0.02 \\
\hline Monthly new visits & 0.0002 & 0.001 & 0.80 \\
\hline Monthly total visits & 0.0001 & 0.0002 & 0.80 \\
\hline $\begin{array}{l}\text { Boldface type indicates statistical significance. } \\
\text { Not significant after } \mathrm{BH} \text { correction. } \\
-1.2 \% \text { per } 10 \text { minutes. } \\
-2.4 \% \text { per } 10 \text { minutes. } \\
-0.9 \% \text { per } 10 \text { minutes. } \\
\pi-2.74 \% \text { per } 10 \text { minutes. } \\
\text { T* }-0.70 \% \text { per } 10 \text { minutes. }\end{array}$ & & & \\
\hline
\end{tabular}




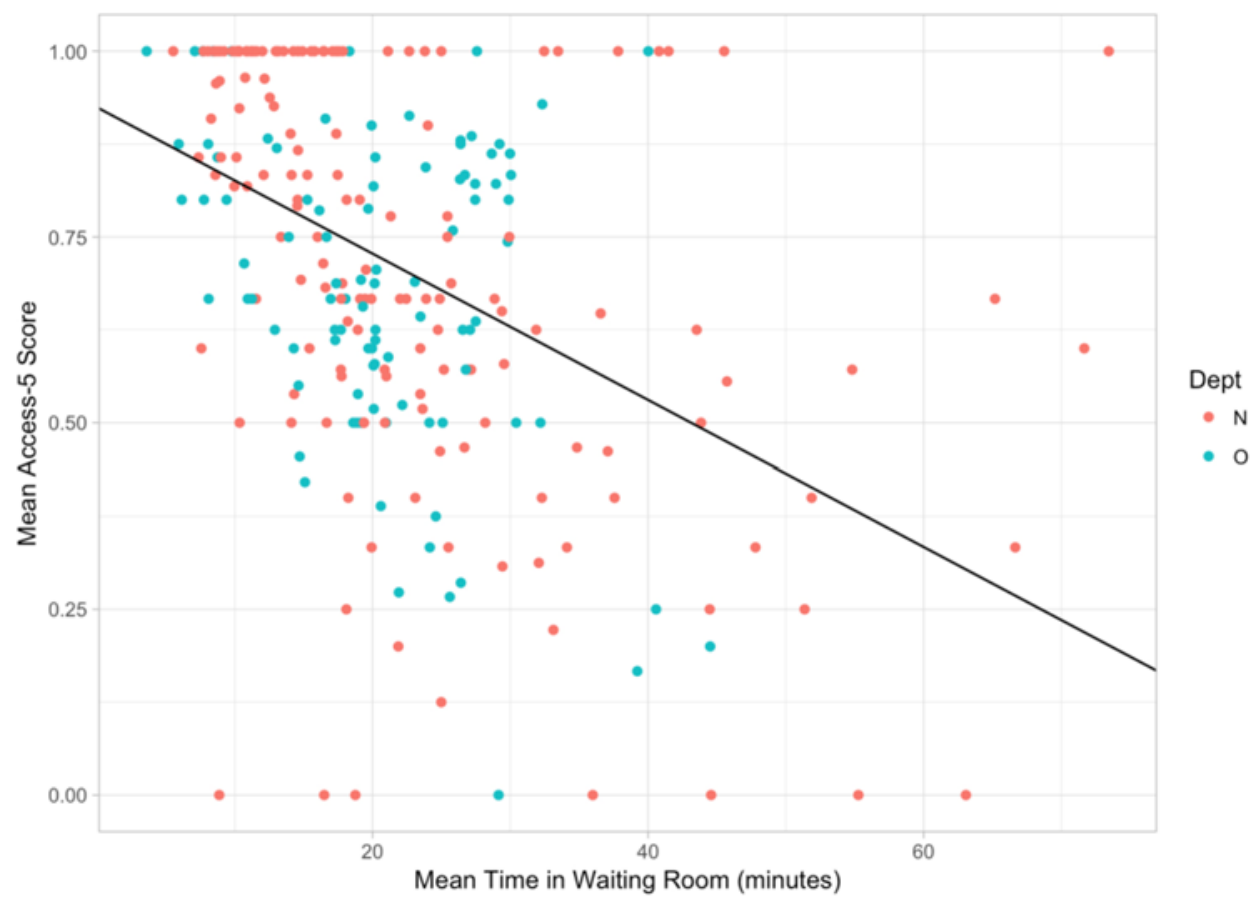

FIG. 3. Communication rating as a function of wait time. Across all providers and encounters, prolonged average waiting time was associated with a $2.37 \%$ absolute reduction in communication rating scores per 10 additional minutes of waiting in univariate mixed-methods regression. Red dots indicate neurosurgery department and blue dots indicate orthopedic surgery department. $R=-0.19, p=0.0041$. Figure is available in color online only.

variable due to monthly means of $100 \%$ or $0 \%$ that limit the interpretation of the slope of the regression.

Despite the unit of analysis being the physician's monthly aggregate and not the patient, there are some missing data if no patient who responded for that month answered a particular question; additionally, there are recently hired providers who supply less than 6 months of data to the analysis. The short period of time on the study may introduce an unmeasured bias related to a provider either being new to the practice or new as an attending. Despite these limitations, our mixed sample of neurosurgical and orthopedic spine surgeons was reasonably consistent across the included practice locations, and we believe that our group constitutes a reasonable sample of academic spine surgeons.

\section{Conclusions}

We found that there were both modifiable and nonmodifiable physician factors that had a significant impact on multiple domains of patient satisfaction, including sex, fellowship training, waiting-room time, and in-room time. The effect of cycle time on nonaccess measures of satisfaction implies that the roots of patient satisfaction are complex, and we have proposed an updated theoretical framework to clarify those relationships. This framework

TABLE 5. Univariate relationships between cycle time and communication scores

\begin{tabular}{lcccccccc}
\hline & \multicolumn{2}{c}{ Cycle Time } & & \multicolumn{2}{c}{ Waiting-Room Time } & & \multicolumn{2}{c}{ In-Room Time } \\
\cline { 2 - 3 } Assessments of Communication & $\% / 10$ Mins & $p$ Value & & $\% / 10$ Mins & $p$ Value & & $\% / 10$ Mins & $p$ Value \\
\hline 1. Clear explanation & $-1.6 \%$ & $<0.001$ & & $-2.7 \%$ & $\mathbf{0 . 0 0 5}$ & & $-1.6 \%$ & $\mathbf{0 . 0 1}$ \\
\hline 2. Careful listening & $-1.4 \%$ & $\mathbf{0 . 0 0 4}$ & & $-3.2 \%$ & $<0.001$ & & $-0.9 \%$ & 0.20 \\
\hline 3. Easy-to-understand information & $-0.7 \%$ & 0.14 & & $-1.3 \%$ & 0.20 & & $-0.5 \%$ & 0.42 \\
\hline 4. Knows medical history & $-1.2 \%$ & $\mathbf{0 . 0 5}$ & & $-1.1 \%$ & 0.16 & & $-1.7 \%$ & 0.12 \\
\hline 5. Respect & $-0.9 \%$ & $\mathbf{0 . 0 3}$ & & $-1.9 \%$ & $\mathbf{0 . 0 2}$ & & $-0.6 \%$ & 0.29 \\
\hline 6. Spent enough time & $-1.7 \%$ & $\mathbf{0 . 0 0 2}$ & & $-3.4 \%$ & $\mathbf{0 . 0 0 2}$ & & $-1.3 \%$ & 0.07 \\
\hline
\end{tabular}

Univariate mixed-model regression results for average cycle time, waiting-room time, and in-room time as independent predictors for each of the 6 individual communication questions. Significance was set to $p<0.05$. Cycle time is the sum of waiting-room and in-room time. Boldface type indicates statistical significance. 
allows us and other practices to not only target specific areas for improvement, such as reducing cycle time, but also tells us where to expect to see an effect, which in the case of cycle time is across all satisfaction measures.

\section{Acknowledgments}

Research reported in this publication was supported by the National Center For Advancing Translational Sciences of the National Institutes of Health under Award Number TL1TR001116. The content is solely the responsibility of the authors and does not necessarily represent the official views of the National Institutes of Health.

\section{References}

1. Almomani I, AlSarheed A: Enhancing outpatient clinics management software by reducing patients' waiting time. J Infect Public Health 9:734-743, 2016

2. Batbaatar E, Dorjdagva J, Luvsannyam A, Amenta P: Conceptualisation of patient satisfaction: a systematic narrative literature review. Perspect Public Health 135:243-250, 2015

3. Batbaatar E, Dorjdagva J, Luvsannyam A, Savino MM, Amenta P: Determinants of patient satisfaction: a systematic review. Perspect Public Health 137:89-101, 2017

4. Beach MC, Sugarman J, Johnson RL, Arbelaez JJ, Duggan PS, Cooper LA: Do patients treated with dignity report higher satisfaction, adherence, and receipt of preventive care? Ann Fam Med 3:331-338, 2005

5. Bell RA, Kravitz RL, Thom D, Krupat E, Azari R: Unsaid but not forgotten: patients' unvoiced desires in office visits. Arch Intern Med 161:1977-1984, 2001

6. Benjamini Y, Hochberg Y: Controlling the false discovery rate: a practical and powerful approach to multiple testing. J R Stat Soc B 57:289-300, 1995

7. Bible JE, Shau DN, Kay HF, Cheng JS, Aaronson OS, Devin CJ: Are low patient satisfaction scores always due to the provider?: Determinants of patient satisfaction scores during spine clinic visits. Spine (Phila Pa 1976) 43:58-64, 2018

8. Boss EF, Thompson RE: Patient satisfaction in otolaryngology: can academic institutions compete? Laryngoscope 122:1000-1009, 2012

9. Chen JG, Zou B, Shuster J: Relationship between patient satisfaction and physician characteristics. J Patient Exp 4:177-184, 2017

10. Chotai S, Sivaganesan A, Parker SL, McGirt MJ, Devin CJ: Patient-specific factors associated with dissatisfaction after elective surgery for degenerative spine diseases. Neurosurgery 77:157-163, 2015

11. Chu H, Westbrook RA, Njue-Marendes S, Giordano TP, Dang BN: The psychology of the wait time experience-what clinics can do to manage the waiting experience for patients: a longitudinal, qualitative study. BMC Health Serv Res 19:459, 2019

12. Cleary PD, McNeil BJ: Patient satisfaction as an indicator of quality care. Inquiry 25:25-36, 1988

13. Davis J, Burrows JF, Ben Khallouq B, Rosen P: Predictors of patient satisfaction in pediatric oncology. J Pediatr Oncol Nurs 34:435-438, 2017

14. Dow CM, Roche PA, Ziebland S: Talk of frustration in the narratives of people with chronic pain. Chronic Illn 8:176191,2012

15. Druss BG, Rosenheck RA, Stolar M: Patient satisfaction and administrative measures as indicators of the quality of mental health care. Psychiatr Serv 50:1053-1058, 1999

16. Fan VS, Burman M, McDonell MB, Fihn SD: Continuity of care and other determinants of patient satisfaction with primary care. J Gen Intern Med 20:226-233, 2005
17. Fernandez E, Turk DC: The scope and significance of anger in the experience of chronic pain. Pain 61:165-175, 1995

18. Finney JW, Humphreys K, Kivlahan DR, Harris AH: Why health care process performance measures can have different relationships to outcomes for patients and hospitals: understanding the ecological fallacy. Am J Public Health 101:1635-1642, 2011

19. Finucane AM: The effect of fear and anger on selective attention. Emotion 11:970-974, 2011

20. Ford EW, Huerta TR, Diana ML, Kazley AS, Menachemi N: Patient satisfaction scores and their relationship to hospital website quality measures. Health Mark Q 30:334-348, 2013

21. Gable PA, Poole BD, Harmon-Jones E: Anger perceptually and conceptually narrows cognitive scope. J Pers Soc Psychol 109:163-174, 2015

22. Gary TL, Maiese EM, Batts-Turner M, Wang NY, Brancati FL: Patient satisfaction, preventive services, and emergency room use among African-Americans with type 2 diabetes. Dis Manag 8:361-371, 2005

23. Gorodeski EZ, Joyce E, Gandesbery BT, Blackstone EH, Taylor DO, Tang WHW, et al: Discordance between 'actual' and 'scheduled' check-in times at a heart failure clinic. PLoS One 12:e0187849, 2017

24. Gray BB: Long waits at the doctor's office disrespect patients. KevinMD.com. May 1, 2012 (https://www.kevinmd. com/blog/2012/05/long-waits-doctors-office-disrespectpatients.html) [Accessed January 13, 2020]

25. Harmelink S: Performance improvement using methodology: case study. Radiol Manage 30:62-65, 2008

26. Horwitz JR: Making profits and providing care: comparing nonprofit, for-profit, and government hospitals. Health Aff (Millwood) 24:790-801, 2005

27. Institute of Medicine (US) Committee on Assuring the Health of the Public in the 21st Century: The Future of the Public's Health in the 21st Century. Washington, DC: National Academies Press, 2002

28. Jensen JD, Allen L, Blasko R, Nagy P: Using quality improvement methods to improve patient experience. J Am Coll Radiol 13 (12 Pt B):1550-1554, 2016

29. Johal J, Dodd A: Physician extenders on surgical services: a systematic review. Can J Surg 60:172-178, 2017

30. Kravitz RL, Bell RA, Azari R, Krupat E, Kelly-Reif S, Thom D: Request fulfillment in office practice: antecedents and relationship to outcomes. Med Care 40:38-51, 2002

31. Kreitz TM, Winters BS, Pedowitz DI: The influence of wait time on patient satisfaction in the orthopedic clinic. J Patient Exp 3:39-42, 2016

32. Lau A, Ewing C, Gnanapragasam J, Majaesic C, MacLean J, Mandhane PJ: Changes to a pediatric sleep disordered breathing clinic improve wait-times and clinic efficiency. Pediatr Pulmonol 51:1234-1241, 2016

33. Levin JM, Winkelman RD, Tanenbaum JE, Benzel EC, Mroz TE, Steinmetz MP: Key drivers of patient satisfaction in lumbar spine surgery. J Neurosurg Spine 28:586-592, 2018

34. Manning BT, Ahn J, Bohl DD, Mayo BC, Louie PK, Singh K: Spine surgeon selection criteria: factors influencing patient choice. Spine (Phila Pa 1976) 41:E814-E819, 2016

35. Marley KA, Collier DA, Goldstein SM: The role of clinical and process quality in achieving patient satisfaction in hospitals. Decis Sci 35:349-369, 2004

36. Medway AM, de Riese WTW, de Riese CS, Cordero J: Why patients should arrive late: the impact of arrival time on patient satisfaction in an academic clinic. Healthc (Amst) 4:188-191, 2016

37. Mehra P: Outpatient clinic waiting time, provider communication styles and satisfaction with healthcare in India. Int J Health Care Qual Assur 29:759-777, 2016

38. Monroe-Wise A, Reisner E, Sherr K, Ojakaa D, Mbau L, Kisia P, et al: Using lean manufacturing principles to evalu- 
ate wait times for HIV-positive patients in an urban clinic in Kenya. Int J STD AIDS 28:1410-1418, 2017

39. Mosadeghrad AM: Patient choice of a hospital: implications for health policy and management. Int J Health Care Qual Assur 27:152-164, 2014

40. Stark C, Gent A, Kirkland L: Improving patient flow in preoperative assessment. BMJ Open Qual 4:u201341.w1226, 2015

41. Stewart MA: Stuck in the middle: the impact of collaborative interprofessional communication on patient expectations. Shoulder Elbow 10:66-72, 2018

42. Tabibian BE, Kuhn EN, Davis MC, Pritchard PR: Patient expectations and preferences in the spinal surgery clinic. World Neurosurg 106:595-601, 2017

43. Waghorn A, McKee M: Understanding patients' views of a surgical outpatient clinic. J Eval Clin Pract 6:273-279, 2000

44. Xie Z, Or C: Associations between waiting times, service times, and patient satisfaction in an endocrinology outpatient department: a time study and questionnaire survey. Inquiry 54:46958017739527, 2017

45. Zakare-Fagbamila RT, Howell E, Choi AY, Cheng TZ, Clement M, Neely M, et al: Clinic satisfaction tool improves communication and provides real-time feedback. Neurosurgery 84:908-918, 2019

\section{Disclosures}

Dr. Gottfried is a medical consultant for Pioneer Surgical Technology, Inc.

\section{Author Contributions}

Conception and design: Zakare-Fagbamila. Acquisition of data: Zakare-Fagbamila, Dickson. Analysis and interpretation of data: Zakare-Fagbamila, Park. Drafting the article: Zakare-Fagbamila, Park. Critically revising the article: Park. Reviewed submitted version of manuscript: Park. Statistical analysis: Zakare-Fagbamila, Cheng. Study supervision: Gottfried.

\section{Supplemental Information}

\section{Previous Presentations}

Portions of this work were given as oral presentations at the following venues: 1) North American Spine Society 34th Annual Meeting, September 25-28, 2019, Chicago, IL; and 2) Spine Summit 35th Annual Meeting, March 14-17, 2019, Miami, FL.

\section{Correspondence}

Oren N. Gottfried: Duke University School of Medicine, Durham, NC. oren.gottfried@duke.edu. 